\section{Pooling in a Pod: A Strategy for COVID- 9 Testing to Facilitate a Safe Return to School}

\author{
Ethan M. Berke, MD, MPH' ${ }^{1}$; Lori M. Newman, MD²; \\ Suzanna Jemsby, MA ${ }^{3}$; Bethany Hyde, MHA'; Natasha Bhalla, MEd ${ }^{3}$; \\ Natalie E. Sheils, PhD $^{1}{ }^{1}$; Nandini Oomman, PhD $^{3}$; John Reppas, $\mathrm{MD}, \mathrm{PhD}^{3}$; \\ Prateek Verma, MS'; and Gerard A. Cangelosi, PhD $^{4}$
}

Public Health Reports 202I, Vol. I36(6) 663-670 (C) 202I, Association of Schools and Programs of Public Health All rights reserved. (c) (1) (8)

Article reuse guidelines: sagepub.com/journals-permissions DOI: $10.1 \mid$ 177/0033354921 1045816 journals.sagepub.com/home/phr

(S)SAGE

\begin{abstract}
The COVID-19 pandemic prompted widespread closures of primary and secondary schools. Routine testing of asymptomatic students and staff members, as part of a comprehensive mitigation program, can help schools open safely. "Pooling in a pod" is a public health surveillance strategy whereby testing cohorts (pods) are based on social relationships and physical proximity. Pooled testing provides a single laboratory test result for the entire pod, rather than a separate result for each person in the pod. During the 2020-202 I school year, an independent preschool-grade I 2 school in Washington, DC, used pooling in a pod for weekly on-site point-of-care testing of all staff members and students. Staff members and older students self-collected anterior nares samples, and trained staff members collected samples from younger students. Overall, 12885 samples were tested in 1737 pools for 863 students and 264 staff members from November 30, 2020, through April 30, 2021. The average pool size was 7.4 people. The average time from sample collection to pool test result was 40 minutes. The direct testing cost per person per week was $\$ 24.24$, including swabs. During the study period, 4 surveillance test pools received positive test results for COVID-19. A post-launch survey found most parents $(90.3 \%)$, students (93.4\%), and staff members $(98.8 \%)$ were willing to participate in pooled testing with confirmatory tests for pool members who received a positive test result. The proportion of students in remote learning decreased by $62.2 \%$ for students in grades $6-12(P<.00 I)$ and by $92.4 \%$ for students in preschool to grade 5 after program initiation $(P<.00 \mathrm{I})$. Pooling in a pod is a feasible, costeffective surveillance strategy that may facilitate safe, sustainable, in-person schooling during a pandemic.
\end{abstract}

\title{
Keywords
}

COVID-19, SARS-CoV-2, school health, testing, surveillance, pooling

The COVID-19 pandemic resulted in widespread closures of schools across the United States during the 2020-2021 school year. Although these closures were intended to minimize the risk of disease transmission, studies show that they may have had an unintentional adverse effect on approximately 56.4 million school-aged children through reduced educational attainment and potential years of life lost. ${ }^{1}$ As of March 2021 , only about half of the student population in the United States was in the classroom, most of whom were in hybrid learning models (ie, part-time in class, part-time in remote learning). ${ }^{2}$ However, some studies suggest that students who are learning in the classroom may be at lower risk of COVID-19 exposure than students learning remotely because of differences in transmissibility or stricter enforcement of face masking and physical distancing at schools than at home and in community settings. ${ }^{3}$ As schools began to plan for the 2021-2022 school year, calls were being made by parents, educators, policy makers, and health professionals for a return to full-time in-person learning. ${ }^{4,5}$ In addition

\footnotetext{
' UnitedHealth Group, Minnetonka, MN, USA

${ }^{2}$ Washington, DC, USA

${ }^{3}$ Washington International School, Washington, DC, USA

${ }^{4}$ Department of Environmental and Occupational Health Sciences, University of Washington, Seattle, WA, USA

Corresponding Author:

Ethan M. Berke, MD, MPH, UnitedHealth Group, 9900 Bren Rd East, Minnetonka, MN 55343, USA.

Email: ethan.berke@uhg.com
} 
to benefits for children from an academic and social standpoint, ${ }^{6-9}$ returning students to full-time in-person learning has value for economically disadvantaged populations and women. ${ }^{10-12}$ Schools will need to have strategies in place that allow for safe in-person attendance for students and staff members and minimize operational disruption.

Strategies to safely keep schools open include screening daily for symptoms, wearing face masks, physical distancing, modifying extracurricular activities, and optimizing facilities to minimize transmission. ${ }^{13}$ Vaccinations also play a critical role in the reduction and spread of disease. It is unlikely that $100 \%$ of staff members and students will be fully vaccinated by the start of the 2021-2022 school year, because of vaccine hesitancy and no availability of vaccines for the youngest age groups. Therefore, asymptomatic spread, which may account for as much as $60 \%$ of transmission in the community, will continue to be a risk. ${ }^{14}$ An effective reopening strategy for schools might also include the routine use of a high-performing SARS-CoV-2 test for all students and staff members, with a turnaround time that allows for rapid decisions. Challenges include access to testing, cost, turnaround time, and policies for addressing positive test results. ${ }^{15}$ Many schools do not currently have the resources or capacity to implement regular testing strategies for all people on campus. ${ }^{16,17}$

Pooling of samples from multiple people is a strategy used by commercial or reference laboratories to increase efficiency. ${ }^{18}$ If the pool yields a negative test result, all samples are assumed to be negative. If the pool yields a positive test result, additional testing is used to identify the infected people in the pool. By combining multiple samples in a single test, more people can be tested at a lower cost compared with testing people individually. Pooling is most cost-effective for diseases with a low prevalence of transmission (eg, HIV, syphilis), in which most pools are expected to receive a negative test result. Because sample dilution may reduce sensitivity, it is critical to use technologies with high analytical sensitivity. ${ }^{19}$

The traditional application of pooling generally does not consider the relationship of the people in the pool with each other or their geographic proximity to each other in an institution or community. ${ }^{20}$ In contrast, pooling in a pod is a public health surveillance strategy in which cohort-specific testing pods are formed according to epidemiologic characteristics, such as social relationships and physical proximity. Pooled testing provides a single laboratory result for the pod rather than a separate result for each person in the pod. In schools, pods may comprise classrooms or staffing clusters (eg, cafeteria workers, administration team). Pooling in a pod uses these natural relationships so that actions taken after a positive test result (eg, contact tracing, confirmatory testing) can be similar for all pod members.

The goal of this demonstration project was to evaluate the feasibility of using a pooling-in-a-pod strategy to reduce the number of COVID-19 infections on a school campus,

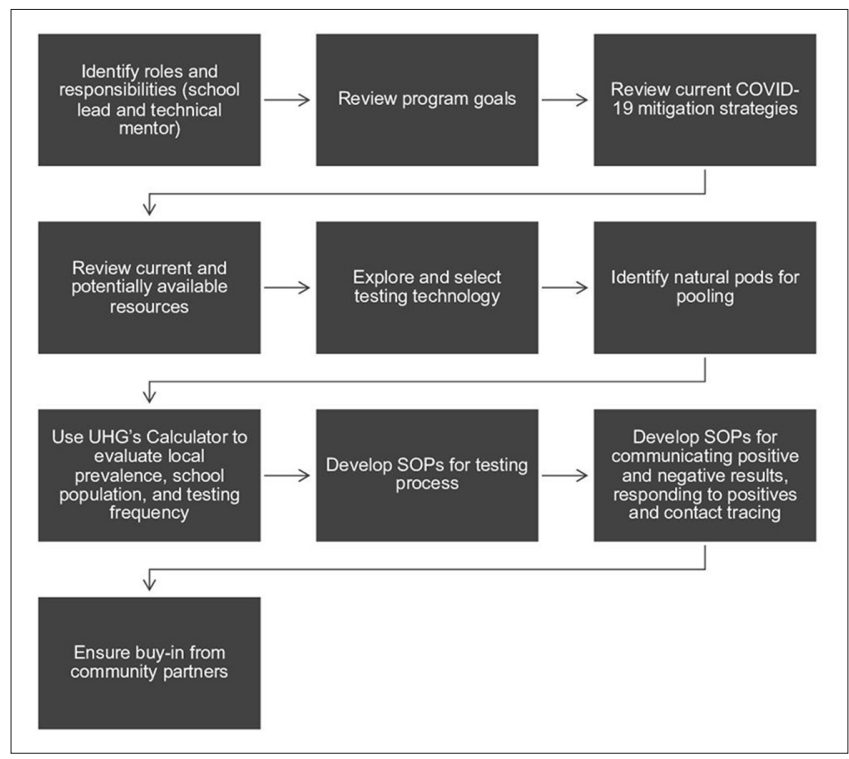

Figure I. Steps required to design and implement a school-based pooling-in-a-pod strategy for COVID-19. Pooling in a pod is a public health surveillance strategy whereby testing cohorts (pods) are based on social relationships and physical proximity. Pooled testing provides a single laboratory test result for the entire pod, rather than a separate result for each person in the pod. (Calculator available at https://calculator.unitedinresearch.com/ complex_dashboard.) Abbreviations: SOP, standard operating procedure; UHG, UnitedHealth Group.

minimize testing resource requirements, and maintain continuity of operations, thereby enabling schools to safely operate in the COVID-19 era. The results will help guide the development of site-appropriate testing strategies for COVID-19 and future infectious disease outbreaks.

\section{Methods}

A nonprofit, independent day school in Washington, DC, with 904 children, 209 faculty and staff members, and additional contractors on 2 school campuses, operating in a hybrid learning model (ie, 1 week of in-person learning, 1 week of remote learning) for students in grades 1-12 and fully in-person for students in preschool and kindergarten was the site of the demonstration project. Students could move between in-person and remote learning. This project was conducted as an institutional review board-approved study with consent from parents and staff members and assent from students. The school and its research partners used intentional design principles to design the project, including outlining project leadership, goals, available resources, scenario planning, operations, and engagement (Figure 1).

An online calculator ${ }^{21}$ compared various hypothetical testing scenarios that allowed the school to weigh the benefits of testing platform performance, testing frequency, cost, 
turnaround time, and pooling based on their operational constraints and program goals. ${ }^{22}$ Weekly testing and symptom tracking using a $\$ 20$ test with $60 \%$ positive agreement and 98\% negative agreement (eg, individual antigen test in asymptomatic people) was estimated to cost $\$ 30.95$ per person per week with confirmatory testing or $\$ 20.45$ without confirmatory testing. Compared with symptom tracking alone, using the testing strategy with symptom tracking would avert the number of infections by $47 \%$ but result in 322 false-positive results during 100 days. In contrast, a $\$ 175$ test with $98 \%$ positive agreement and $99.5 \%$ negative agreement (eg, real-time polymerase chain reaction test) with same-day results administered weekly using pooling in a pod with 14 people per pool was estimated to cost $\$ 21.57$ per person per week with confirmatory testing, or $\$ 13.17$ without confirmatory testing. This approach would reduce infections by $98 \%$ but result in 82 false-positive results during 100 days.

Based on this exercise, the school selected the portable, single-use Visby Medical COVID-19 test (Visby Medical), with performance similar to other nucleic acid amplification tests (NAATs), ${ }^{23,24}$ but conducted on-site with a 30-minute turnaround time. The device was validated for pool sizes of 5-25 people; the limit of detection was 2000 genomic copies/ $\mathrm{mL}$ at 15 swabs per pool. ${ }^{25}$ The test was used according to federal guidance for pooled testing. ${ }^{26,27}$ All swabs were introduced directly into a single buffer vial to minimize dilution during pooling. ${ }^{19}$ The target pool sizes of 8-14 for students and 4-6 for teachers and staff members were based on class size, schedule, and the estimated number of daily new cases of COVID-19 in Washington, DC. The range of 10-46 new cases per 100000 population during the study period corresponded to a moderate-to-substantial community transmission risk. ${ }^{28}$ The school required all people on campus to have a weekly negative test result to enter campus, either through the school pooled testing program at no cost to the participant or through individual NAATs at the same frequency at their own expense. Alternatively, students could opt for remote learning only.

After a 1-day on-site training, the school operated all daily aspects of the testing program including sample collection, device operation, data logging in secure software, and communications (Figure 2). Pods were designed at the school's discretion to align to its operational needs and comprised students only, staff members only, or a mix of students and staff members depending on grade and schedule. Students tested twice per week when attending school inperson and did not test during their remote week in the hybrid model, resulting in an average testing frequency of once per week. Staff members and younger students in full-time onsite learning tested weekly. If a student or staff member was absent during a regular testing event, or if a substitute teacher came to campus midweek, that person was tested upon arrival on campus. Students in grades 6-12 and all staff members self-collected anterior nares samples, ${ }^{29}$ and a trained clinician collected anterior nasal samples from students in preschool to grade 5 .

Pooled, not individual, results were communicated to staff members and families via a single community-wide email update after each round of testing. If a student pool received a negative test result, all pod members remained on campus. If a student pool received a positive test result, students in that pool were sent home and advised to seek an NAAT in a clinical setting. If a staff member pool received a positive test result, all participants in that pool were asked to provide additional samples for subpooling, which minimized the number of staff members adversely affected by being in a positive pool. When a staff member subpool received a positive test result, members were confidentially advised to seek NAATs covered by employer health insurance. Students and staff members in a pool with a positive test result could not return until a negative NAAT result was available.

We calculated the weekly direct per-person cost of the program by identifying the cost per person per week, including swab and test device, and applying a weighted average to calculate the overall per-person cost. We surveyed parents of students in grades 6-12 and staff members after 3 weeks of testing using the school's electronic method of survey collection for families. Many parents and staff members did not speak English as a first language. As such, communication routinely included slides with clear directions and nonverbal images and was conducted by multilingual staff members in English, French, and Spanish.

\section{Outcomes}

From November 30, 2020, through April 30, 2021, 863 students and 264 staff members and contractors participated at least once in the testing program (Table 1). Students in grades 6-12 started testing in November 2020, and younger students started participating on January 21, 2021. Students in grades 6-12 tested an average of 11.5 times (range, 1-17), students in pre-kindergarten to fifth grade tested an average of 10.6 times (range, 1-17), and staff members tested an average of 12.7 times (range, 1-25). Up to 542 students and 207 staff members were tested each session; a total of 12885 samples were tested in 1737 pools. Of all students who came to campus during the study period, only 1 student chose to provide external proof of a negative NAAT on a weekly basis instead of participating in the program. The average pool size was 7.4 people (range, 2-17). The average testing time from sample collection to result was 40 minutes.

During more than 34 testing sessions in the study period, 1733 pools received a negative test result and 4 pools received a positive test result. One pool of 4 staff members received a positive test result; outside individual confirmatory testing with NAAT identified a single positive asymptomatic person. A second pool of 4 staff members with a positive test result was determined to be a false-positive 


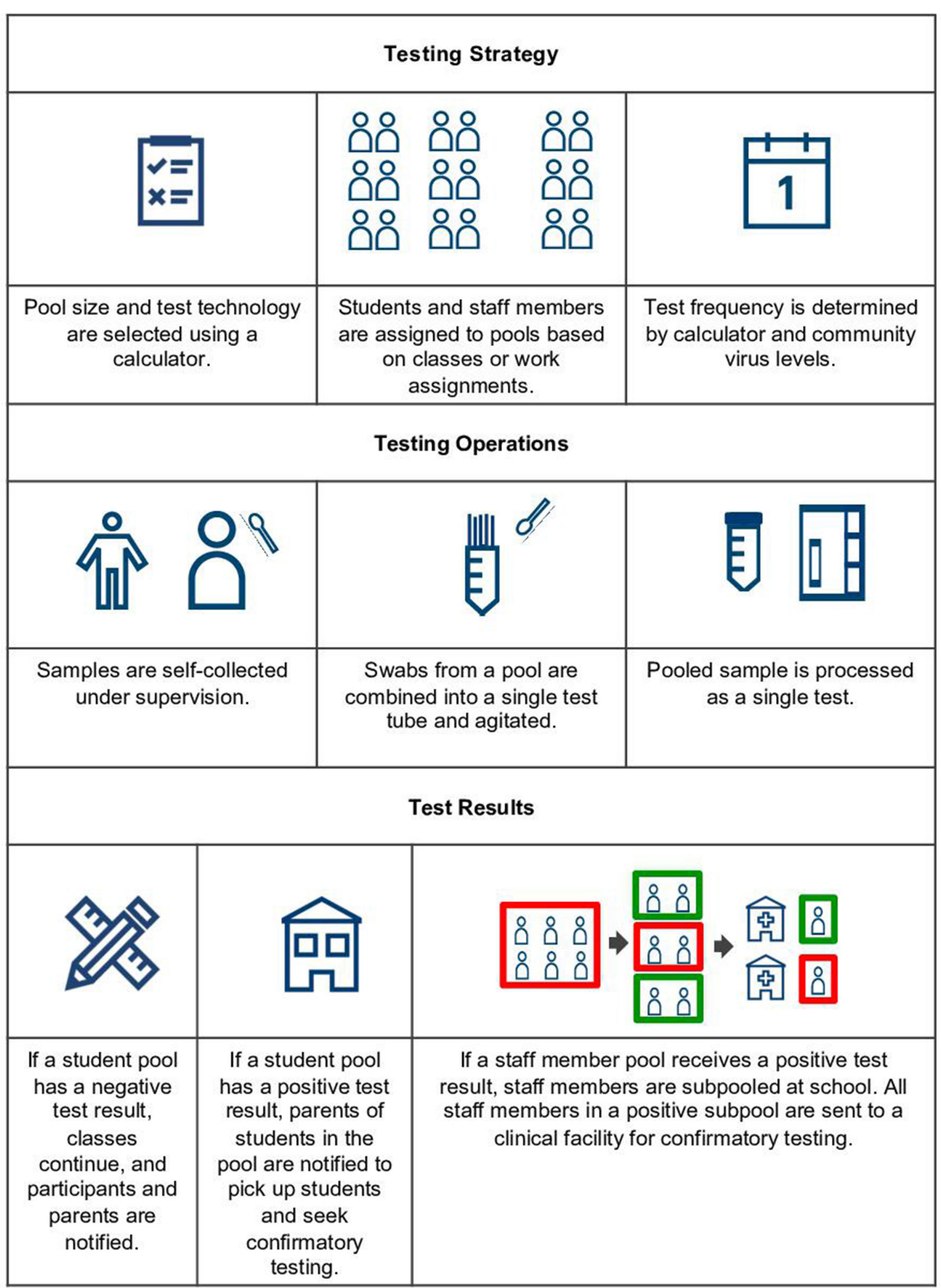

Figure 2. Operational flowchart for pooling-in-a-pod testing of faculty, staff members, and students. Pooling in a pod is a public health surveillance strategy whereby testing cohorts (pods) are based on social relationships and physical proximity. Pooled testing provides a single laboratory test result for the entire pod, rather than a separate result for each person in the pod. (Calculator available at https:// calculator.unitedinresearch.com/complex_dashboard.) 
Table I. Participation of student and staff member pods in a COVID-19 pooling-in-a-pod testing program, Washington, DC, 2020-202/ ${ }^{\mathrm{a}}$

\begin{tabular}{|c|c|c|c|c|}
\hline Pods & $\begin{array}{l}\text { No. participating in } \\
\text { testing at least once }\end{array}$ & $\begin{array}{l}\text { No. of sessions } \\
\text { (mean, range) }\end{array}$ & $\begin{array}{c}\text { Average pool size, } \\
\text { no. (range) }\end{array}$ & $\begin{array}{l}\text { Total no. of pools (no. } \\
\text { with a positive test result) }\end{array}$ \\
\hline Staff members & 264 & $12.7(\mid-25)$ & $6.6(2-13)$ & $418(2)$ \\
\hline Students in grades $6-12$ & 442 & $11.5(1-17)$ & $7.6(2-17)$ & $670(0)$ \\
\hline Students in preschool-grade 5 & 421 & $11.6(1-17)$ & $8.1(3-16)$ & $160(2)$ \\
\hline $\begin{array}{l}\text { Mixed student and staff } \\
\text { members }\end{array}$ & NA & NA & $10.8(2-17)$ & $489(0)$ \\
\hline Total & 1127 & II.8 (I-25) & $7.4(2-17)$ & 1737 (4) \\
\hline
\end{tabular}

Abbreviation: NA, not applicable.

a Pooling in a pod is a public health surveillance strategy whereby testing cohorts (pods) are based on social relationships and physical proximity. Pooled testing provides a single laboratory test result for the entire pod, rather than a separate result for each person in the pod.

result based on follow-up subpooling and outside confirmatory testing with NAAT. Two pools of students received a positive test result; all students provided individual confirmatory NAAT results, and in each positive pool a single asymptomatic positive student was identified. One student reported receiving a positive test result from an outside test during the study period, 4 days after receiving a negative test result in the pool. Four people received a positive test result during the holiday break, when no school testing was being performed. No confirmed cases of transmission occurred on the school campus. The weekly direct per-person cost of the program was $\$ 24.24$.

Table 2. Parent, student, and staff member attitudes toward weekly pooled testing for COVID-I9 in a school environment in a survey administered 3 weeks after program initiation, December 2020, Washington, DC ${ }^{a}$

\begin{tabular}{|c|c|c|c|}
\hline \multirow[b]{2}{*}{ Question } & \multicolumn{3}{|c|}{ Agree or strongly agree, \% } \\
\hline & $\begin{array}{l}\text { Parents } \\
(n=309)\end{array}$ & $\begin{array}{c}\text { Students (grades 6- } 12) \\
(\mathrm{n}=88)\end{array}$ & $\begin{array}{l}\text { Staff members } \\
\qquad(n=84)\end{array}$ \\
\hline Response rate, \% & 24 & 19 & 38 \\
\hline $\begin{array}{l}\text { Testing students, staff members, and faculty } \\
\text { on a regular basis is important to ensure } \\
\text { that school can remain open and the WIS } \\
\text { [Washington International School] community } \\
\text { can be as safe as possible. }\end{array}$ & 92 & 95 & 93 \\
\hline $\begin{array}{l}\text { Pre-launch: I am open to being part of a pooled } \\
\text { testing protocol once or twice a week, with } \\
\text { an individual confirmatory test required if the } \\
\text { pool is positive. }\end{array}$ & 89 & 88 & 92 \\
\hline $\begin{array}{l}\text { Post-launch: I am open to being part of a pooled } \\
\text { testing protocol once or twice a week, with } \\
\text { an individual confirmatory test required if the } \\
\text { pool is positive. }\end{array}$ & 90 & 93 & 99 \\
\hline $\begin{array}{l}\text { I feel that students or faculty who refuse to be } \\
\text { tested individually or as part of a pool on a } \\
\text { frequent basis should not be allowed to attend } \\
\text { in-person classes. }\end{array}$ & 80 & 83 & 74 \\
\hline $\begin{array}{l}\text { After being trained, I am comfortable collecting } \\
\text { my own sample under observation at the } \\
\text { school. }\end{array}$ & Not applicable & 88 & 96 \\
\hline $\begin{array}{l}\text { I believe the testing program increases my } \\
\text { comfort with the school moving toward full, } \\
\text { in-person learning, even if other schools in the } \\
\text { area remain in hybrid or stay-at-home models. }\end{array}$ & 82 & 76 & 65 \\
\hline $\begin{array}{l}\text { Now that I have been tested, I believe it is just as } \\
\text { important to wear a face mask, wash hands, } \\
\text { and maintain physical distancing. }\end{array}$ & Not applicable & 92 & 96 \\
\hline
\end{tabular}

a Pooling in a pod is a public health surveillance strategy whereby testing cohorts (pods) are based on social relationships and physical proximity. Pooled testing provides a single laboratory test result for the entire pod, rather than a separate result for each person in the pod. 
Three hundred nine parents, 88 students, and 84 staff members responded to the survey (Table 2). After the program was launched, most parents (90\%), students (93\%), and staff members $(99 \%)$ were open to participating in a pooled testing protocol once or twice per week. Parents, students, and staff members reported increased comfort with inperson learning $(82 \%, 76 \%$, and $65 \%$, respectively). Comments included the need for accurate, rapid results; a testing program that included everyone on campus; and minimized disruption to learning. Concerns centered on privacy, confidentiality, and responsibility for confirmatory testing. Before implementation of the testing program on November 30,2020 , 90 students in grades 6-12 were in a remotelearning model. As of April 30, 2021, only 34 students remained in a remote-learning model; similarly, as of November 30, 2020, 53 primary school students were in remote learning and, as of April 30, 2021, four students were in remote learning. Pooling-in-a-pod testing corresponded to a $62.2 \%$ decrease in remote learning for students in grades $6-12(P<.001)$ and a $92.4 \%$ decrease in remote learning for students in preschool to grade 5 after initiation of the program $(P<.001)$.

\section{Lessons Learned}

Pooling in a pod allows for more accessible COVID-19 testing in primary and secondary schools compared with individual testing. This approach balances cost and convenience while optimizing turnaround time, frequency, and performance compared with other testing strategies, such as nonpooled approaches. The program had a high rate of acceptance and increased student, staff member, and parent comfort with in-person attendance. It enables maximal on-campus learning within the framework of local restrictions. This program identified 3 asymptomatic infections, possibly averting ongoing transmission.

Pooling-in-a-pod testing reduces costs and increases processing efficiency as compared with individual testing. By assembling pods based on social relationships and physical proximity, particularly when coupled with rapid turnaround time of test results, schools can make rapid decisions that can preserve continuity of operations. Pooled testing reduces the number of tests required and, therefore, the cost of screening for asymptomatic people with a positive test result in a school. Although the school in our study required individual confirmatory diagnostic testing (and shifted this cost to health insurance or publicly funded testing programs), other schools may instead use quarantine or isolation to further reduce organizational costs. ${ }^{30}$

It is widely believed that COVID-19 will become an endemic disease with intermittent regional outbreaks. ${ }^{31}$ Even as progressively larger numbers of teachers and students are vaccinated, vaccination of all schoolchildren will take time. Not all members of a school community may be vaccinated, and it is not yet clear what the risk of asymptomatic shedding is among vaccinated people, the role variants may play in asymptomatic transmission, and whether booster vaccines will be required. Given the increasing body of evidence suggesting the negative effects of remote learning on students, families, and society, and the expected presence of COVID-19 in the community, introduction of school surveillance testing programs may be a useful investment to fully open school in the fall and stay open throughout the school year, complementing other mitigation efforts that include vaccinations.

This program was implemented with only 1 month of lead time, which could be shortened through adaptation of existing protocols and educational materials. Pooling in a pod could be scaled up rapidly with funding, leadership, and support from federal, private, and nonprofit partners in health and education, even in settings such as public schools, where implementation and workforce capacity are limited. Rapid rollout of pooling in a pod may also help in the public health response to future pandemics. Despite positive acceptance of the program by the school community, achieving high participation rates to identify asymptomatic cases may require reexamination of school policies that mandate testing to be on campus, or using an opt-out rather than opt-in consent process.

This study had 2 limitations. First, the overall high approval rate of the program may not be generalizable to other settings and may be biased by a low survey response rate (parents: $24 \%$, students: $19 \%$; staff members: $24 \%$ ). Second, indirect costs were not included in actual cost estimates; the primary indirect cost was program staffing. Many schools will require more human and financial resources to implement a testing program than were required for this demonstration project. However, pooled testing can reduce the cost of a testing program through gains in efficiency. Onsite or near-site high-throughput testing platforms may further reduce costs with a minimal loss of turnaround time. Tools that allow comparisons of cost, performance, and test frequency, such as online calculators, ${ }^{21}$ can help schools make these strategic decisions.

Pooling in a pod could be a cost-effective, feasible, and acceptable surveillance testing strategy for primary and secondary schools to safely operate in-person learning when combined with other interventions to reduce the transmission of SARS-CoV-2. Other innovations, including on-site and near-site dedicated laboratories, could be developed to facilitate pooled testing on a national scale. Pooling-in-a-pod public health surveillance could also be implemented for businesses and other institutions where in-person presence is essential.

\section{Acknowledgments}

The authors acknowledge the following for their contributions to the design, implementation, participation, analysis, and/or preparation of the article: students, parents, and staff members of the Washington 
International School; Bruce Tromberg, $\mathrm{PhD}$, National Institute of Biomedical Imaging and Bioengineering, National Institutes of Health; and Michael Iademarco, MD, MPH, RADM, US Public Health Service, Center for Surveillance, Epidemiology, and Laboratory Services, Centers for Disease Control and Prevention.

\section{Declaration of Conflicting Interests}

The authors declared no potential conflicts of interest with respect to the research, authorship, and/or publication of this article.

\section{Funding}

The authors received no financial support for the research, authorship, and/or publication of this article.

\section{ORCID iDs}

Ethan M. Berke, MD, MPH (D) https://orcid.org/0000-0003-08058218

Natalie E. Sheils, PhD (iD https://orcid.org/0000-0002-0631-5834

\section{References}

1. Christakis DA, Van Cleve W, Zimmerman FJ. Estimation of US children's educational attainment and years of life lost associated with primary school closures during the coronavirus disease 2019 pandemic. JAMA Netw Open. 2020;3(11):e2028786. doi: 10.1001/jamanetworkopen.2020.28786

2. Oster E; National Association of Elementary School Principals, National Association of Secondary School Principals, AASAThe School Superintendents Association. COVID-19 school response dashboard. Accessed January 28, 2021. https://statsiq. co1.qualtrics.com/public-dashboard/v0/dashboard/5f78e 5d4de52 1a001036f78e\#/dashboard/5f78e5d4de521a001036f78e?pageId= Page c0595a5e-9e70-4df2-ab0c-14860e84d36a

3. Centers for Disease Control and Prevention. Science brief: transmission of SARS-CoV-2 in K-12 schools. Updated July 9, 2021. Accessed February 12, 2021. https://www. cdc.gov/coronavirus/2019-ncov/more/science-and-research/ transmission_k_12_schools.html

4. Schnell M. Fauci says school should be open "full blast" five days a week in the fall. The Hill. May 13, 2021. Accessed May 25, 2021. https://thehill.com/policy/healthcare/553494-faucisays-school-should-be-open-full-blast-five-days-a-week-inthe-fall

5. Goldstein D. President of key teachers' union shares plea: "schools must be open" in fall. The New York Times. May 13, 2021. Accessed May 25, 2021. https://www.nytimes.com/2021/ 05/13/us/reopening-schools-teachers-union.html

6. Stein P. This entire second-grade D.C. class fell behind in reading. Now what? The Washington Post. December 1, 2020. Accessed January 28, 2021. https://www.washingtonpost. com/local/education/learning-to-read-on-zoom/2020/12/01/ 50718514-2b78-11eb-9b14-ad872157ebc9_story.html

7. Buonsenso D, De Rose C, Moroni R, Valentini P. SARS-CoV-2 infections in Italian schools: preliminary findings after 1 month of school opening during the second wave of the pandemic. Front Pediatr. 2020;8:615894. doi:10.3389/fped.2020.615894

8. Lee J. Mental health effects of school closures during COVID-19. Lancet Child Adolesc Health. 2020;4(6):421. doi: 10.1016/S2352-4642(20)30109-7

9. Loades ME, Chatburn E, Higson-Sweeney N, et al. Rapid systematic review: the impact of social isolation and loneliness on the mental health of children and adolescents in the context of COVID-19. J Am Acad Child Adolesc Psychiatry. 2020;59(11):1218-1239. doi:10.1016/j.jaac. 2020.05.009

10. Bateman N. Working parents are key to COVID-19 recovery. Brookings Institution. Accessed January 22, 2021. https:/www. brookings.edu/research/working-parents-are-key-to-covid-19recovery

11. Hsu A. "This is too much:" working moms are reaching the breaking point during the pandemic. NPR. September 29, 2020. Accessed January 22, 2021. https://www.npr.org/2020/09/29/ 918127776/this-is-too-much-working-moms-are-reaching-thebreaking-point-during-the-pandemic

12. Oster E, Jack R, Halloran C, et al. Disparities in learning mode access among K-12 students during the COVID-19 pandemic, by race/ethnicity, geography, and grade levelUnited States, September 2020-April 2021. MMWR Morb Mortal Wkly Rep. 2021;70(26):953-958. doi:10.15585/ mmwr.mm7026e2

13. Centers for Disease Control and Prevention. Operational strategy for K-12 schools through phased mitigation. Updated May 15, 2021. Accessed May 25, 2021. https://www.cdc. gov/coronavirus/2019-ncov/community/schools-childcare/ operation-strategy.html

14. Johansson MA, Quandelacy TM, Kada S, et al. SARS-CoV-2 transmission from people without COVID-19 symptoms. JAMA Netw Open. 2021;4(1):e2035057. doi:10.1001/jamanetw orkopen.2020.35057

15. Rafiei Y, Mello MM. The missing piece-SARS-CoV-2 testing and school reopening. $N$ Engl J Med. 2020;383(23):e126. doi: 10.1056/NEJMp2028209

16. Burke M. Los Angeles Unified will offer coronavirus testing to all students, staff in unprecedented effort. August 17, 2020. Accessed January 22, 2021. https://edsource.org/2020/losangeles-unified-will-offer-coronavirus-testing-to-all-studentsstaff-in-unprecedented-effort/638448

17. Silva C. New York City schools will reopen with new COVID-19 testing protocol. NPR. November 29, 2020. Accessed January 22, 2021. https://www.npr.org/sections/coronavirus-live-updates/ 2020/11/29/939902582/new-york-city-schools-will-reopen-withnew-covid-19-testing-protocol

18. Abdalhamid B, Bilder CR, McCutchen EL, Hinrichs SH, Koepsell SA, Iwen PC. Assessment of specimen pooling to conserve SARS CoV-2 testing resources. Am J Clin Pathol. 2020;153(6):715-718. doi:10.1093/ajcp/aqaa064

19. Perchetti GA, Sullivan KW, Pepper G, et al. Pooling of SARSCoV-2 samples to increase molecular testing throughput. J Clin Virol. 2020;131:104570. doi:10.1016/j.jcv.2020.104570 
20. Dorfman R. The detection of defective members of large populations. Ann Math Stat. 1943;14(4):436-440. doi:10.1214/ aoms/1177731363

21. UnitedHealth Group. COVID-19 testing strategy simulator. Accessed October 15, 2020. https://calculator.unitedinresearch. com

22. Lyng GD, Sheils NE, Kennedy CJ, Griffin DO, Berke EM. Identifying optimal COVID-19 testing strategies for schools and businesses: balancing testing frequency, individual test technology, and cost. PLoS One. 2021;16(3):e0248783. doi:10. 1371/journal.pone. 0248783

23. US Food and Drug Administration. Visby Medical COVID-19 point of care test. February 8, 2021. Accessed February 12, 2021. https://www.fda.gov/media/145914/download

24. US Food and Drug Administration. SARS-CoV-2 reference panel comparative data. December 17, 2020. Accessed February 12, 2021. https://www.fda.gov/medical-devices/coronaviruscovid-19-and-medical-devices/sars-cov-2-reference-panelcomparative-data

25. Hyde B, Verma P, Berke EM. Pooled sample testing for SARSCoV-2 using rapid RT-PCR COVID-19 tests (preprint January 26, 2021). medRxiv. doi:10.1101/2021.01.22.21250339
26. Centers for Medicare \& Medicaid Services. Frequently asked questions: SARS-CoV-2 surveillance testing. Accessed January 20, 2021. https:/www.cms.gov/files/document/06-192020-frequently-asked-questions-covid-surveillance-testing. pdf

27. US Food and Drug Administration. Pooled sample testing and screening testing for COVID-19. Accessed February 12, 2021. https://www.fda.gov/medical-devices/coronavirus-covid-19and-medical-devices/pooled-sample-testing-and-screeningtesting-covid-19

28. District of Columbia. Reopening metrics. Accessed May 18, 2021. https://coronavirus.dc.gov/page/reopening-metrics

29. Tu Y-P, Jennings R, Hart B, et al. Swabs collected by patients or health care workers for SARS-CoV-2 testing. $N$ Engl J Med. 2020;383(5):494-496. doi:10.1056/NEJMc2016321

30. Centers for Disease Control and Prevention. Quarantine and isolation. Updated July 29, 2021. Accessed February 9, 2021. https:/www.cdc.gov/coronavirus/2019-ncov/if-you-are-sick/ isolation.html

31. Phillips N. The coronavirus is here to stay-here's what that means. Nature. 2021;590(7846):382-384. doi:10.1038/d41586021-00396-2 